\title{
Disgust Propensity as a Predictor of Intrusive Cognitions Following a Distressing Film
}

\author{
Jessica Bomyea $\cdot$ Nader Amir
}

Published online: 29 August 2010

(c) The Author(s) 2010. This article is published with open access at Springerlink.com

\begin{abstract}
Although extant research examining predictors of development of Posttraumatic Stress Disorder (PTSD) have focused primarily on fear and anxiety, recent research suggests that a range of different emotional reactions may occur in response to traumatic events. For example, specific aspects of traumatic exposure frequently include either experiencing or witnessing events that may elicit disgust, including injury, death, or sexual assault (e.g., Dalgleish and Power in Behav Res Ther Spec Issue Festschrift Spec Issue John Teasdale 42(9):1069-1088, 2004); McNally in J Anxiety Disord 16(5):561-566, 2002). However, no published research has specifically examined the role of disgust propensity in the development and maintenance of PTSD. Thus, the aim of the present study was to evaluate the relationship between disgust propensity and intrusive symptoms. To this end, 30 undergraduates without symptoms of PTSD were recruited to participate in a distressing film paradigm (for a review of this paradigm see Holmes and Bourne in Acta Psychol 127(3):553-566, 2008). Anxiety, depression, and trait disgust scores were entered hierarchically into a regression equation to predict the number of intrusions during a post-film thought monitoring period. Results indicated that disgust propensity predicted intrusions independent of anxiety and depression. Although still preliminary, results suggest that disgust propensity may be one factor that predicts frequency of intrusive memories after witnessing injury or bodily harm.
\end{abstract}

Keywords Disgust · Trauma · Intrusions · PTSD

J. Bomyea $\cdot$ N. Amir $(\bowtie)$

Joint Doctoral Program in Clinical Psychology,

San Diego State University/University of California,

San Diego, CA 921020-4913, USA

e-mail: namir@mail.sdsu.edu
Posttraumatic stress disorder (PTSD) occurs in response to a traumatic or life threatening event that evokes feelings of fear, helplessness, or horror, and is characterized by chronic patterns of avoidance, re-experiencing, and hyperarousal (American Psychiatric Association 2000). Although epidemiological studies indicate that as many as $81 \%$ of individuals will experience an event that meets the DSM-IV definition of a traumatic event, prevalence rates indicate that less than $8 \%$ of individuals will develop PTSD (Kessler et al. 1995; Stein et al. 1997). In line with cognitive models of PTSD (e.g., Brewin et al. 1996; Ehlers and Clark 2000; Foa and Kozak 1986), research suggests that predisposing emotional characteristics (e.g., pre-trauma psychopathology; Brewin et al. 2000b) and biases in processing trauma-related information (e.g., dissociation; Ozer et al. 2003), are critical to the development and maintenance of PTSD. However, these prevailing conceptualizations primarily consider fear and anxiety responses to trauma. Although research suggests that the intensity of emotional reactions of fear, helplessness and horror during trauma do predict PTSD development (Brewin et al. 2000a), traumatic experiences may also elicit other complex emotional reactions that are associated with subsequent PTSD (e.g., shame and anger; Andrews et al. 2000).

One emotion that may play a role in trauma response is disgust (e.g., McNally 2002). Disgust is an emotional reaction that facilitates behavioral avoidance of potential sources of contamination or disease (e.g., Olatunji et al. 2007e). Although disgust is frequently considered in a gustatory context, disgust reactions can also be conceptualized as rejection of unwanted objects from the self (Rozin et al. 1994), or a defensive reaction for preventing physical or psychological harm (Haidt et al. 1994). Research indicates that disgust reactions can be elicited by food related stimuli, but also occur in response to non-gustatory triggers 
such as animals, body envelope violations, and death (e.g., Olatunji et al. 2007e). Similarly, disgust may be elicited by moral and interpersonal stimuli that are perceived as violating social mores (Haidt et al. 1997). Recent work in this area indicates that there may be two distinct components of disgust: disgust sensitivity, or the extent to which an individual is bothered by feeling disgust, and disgust propensity, or the trait-like tendency for an individual to feel disgusted easily or by many types of stimuli (e.g., Fergus and Valentiner 2009). Although a number of studies indicate that both disgust sensitivity and propensity are associated with aversion responses in anxiety and phobias (e.g., Fergus and Valentiner 2009; Olatunji et al. 2007c), the present study will focus on individuals' likelihood of experiencing disgust reactions (i.e., disgust propensity) in the context of exposure to potentially traumatic experiences.

Specific aspects of traumatic exposure frequently include either experiencing or witnessing events that may elicit disgust (Dalgleish and Power 2004; McNally 2002). For example, injury, or dismemberment may occur as a result of combat, car accidents, physical assaults, or natural disasters. Extant literature suggests that witnessing these types of injuries, including seeing blood, bones or bodily tissue, can elicit disgust reactions (e.g., Olatunji et al. 2005, 2008; Olatunji and Sawchuk 2005). Moreover, experiences perceived as immoral, including acts or individuals that are deemed inappropriate or irreprehensible (e.g., incest, molesters), may also lead individuals to feel disgust (e.g., Olatunji and Sawchuk 2005; Tybur et al. 2009). Relevant to traumatic experiences, research indicates that unwanted sexual contact may be associated with feelings of disgust (e.g., Feldner et al. 2010; Petrak et al. 1997). A number of studies also indicate that unwanted sexual contact may elicit feelings of mental pollution or contamination that may be similar to disgust (e.g., Herba and Rachman 2007; Fairbrother and Rachman 2004; Fairbrother et al. 2005; Olatunji et al. 2008a; although see Radomsky and Elliott 2009). Thus, given that traumatic events frequently involve exposure to disgust-eliciting environmental cues, it follows that an individual's propensity to experience disgust reactions may influence their responses to trauma.

In spite of evidence that disgust may be elicited by traumatic events, relatively little work has specifically examined the role of trait disgust in the development and maintenance of PTSD. However, heightened levels of disgust are associated with specific fears (e.g., spiders; de Jong and Muris 2002; Woody et al. 2005; blood-injuryinjection fears, Olatunji 2007c; Sawchuk et al. 2002) and obsessive compulsive disorder (e.g., Olatunji et al. 2004; Tolin et al. 2006). Trait anxiety and disgust also appear to be distinct emotional phenomena that independently predict symptoms of Obsessive Compulsive Disorder (OCD) and specific phobias (Olatunji et al. 2007d), suggesting that disgust propensity is not simply a facet of elevated anxiety. At least one study indicates that individuals with PTSD may also be marked by heightened levels of disgust. Foy et al. (1984) evaluated disgust in a sample of 21 Vietnam veterans with PTSD and 22 veterans without. The authors administered a problem checklist to veterans, including an item indicating level of trait disgust. Results revealed that trait disgust was one among several items that correctly categorized $90 \%$ of the individuals as PTSD positive or negative. Thus, these findings suggest that combat-exposed veterans with PTSD exhibit elevated levels of disgust relative to those without PTSD.

In addition, extant research suggests that traumatic experiences elicit disgust in individuals with PTSD. Research indicates that, for at least a portion of individuals, the primary emotion reportedly experienced during trauma is disgust (Hathaway et al. 2010). Studies indicate that relative to individuals without PTSD, those with PTSD report greater levels of disgust during script driven imagery of their traumatic event (Shin et al. 1999), and that this effect may be particularly pronounced in women (Olatunji et al. 2009a). Findings from Feldner et al. (2010) also indicate that individuals with PTSD experience disgust pertaining to their traumatic event. Using a sample of adolescents with a history of physical and/or sexual assault, the authors retrospectively assessed for presence and intensity of disgust reactions, in addition to fear and helplessness, during the traumatic event. Results indicated that a portion of these individuals endorsed experiencing disgust during the trauma, particularly for sexual assault experiences ( 9.5 and $59.3 \%$, for physical and sexual assault respectively). Taken together, these findings indicate that individuals with PTSD experience feelings of disgust associated with their traumatic events.

However, extant research in this area has only evaluated disgust reactions in individuals who have already developed PTSD. Thus, these studies cannot determine if elevated propensity to experience disgust reactions is simply a correlate of PTSD. Alternatively, individuals who are more prone to experience disgust may be more vulnerable to development of symptoms of PTSD following a traumatic event. For example, disgust appears to be associated with vivid imagery and sensation (Woody and Teachman 2000). It is possible that those individuals who experience greater disgust during a traumatic event may experience memories of the event as more vivid or real. As a result, these disgustprone individuals may be more vulnerable to later reexperiencing symptoms that are considered the hallmark of PTSD. Given ethical concerns with exposing individuals to traumatic events and practical difficulties in obtaining individuals immediately prior to trauma exposure, one methodology frequently used in preliminary studies examining predictors of trauma response is the distressing 
film paradigm (for a review see Holmes and Bourne 2008). In this paradigm, participants are brought into the laboratory and shown film clips containing scenes of trauma, such as car accidents, physical assault, or rape. After viewing the film, participants are typically asked to provide ratings of emotional reactions and record the frequency of intrusive thoughts about the film over a specified period of time.

This methodology has been used to evaluate the contribution of trait emotional characteristics in the development of intrusive thoughts after an analogue stressor (e.g., Laposa and Alden 2008; Regambal and Alden 2009). For example, Laposa and Alden (2008) administered questionnaires assessing trait anxiety, depression, and trait dissociation to a sample of healthy participants. Next, they asked each participant to view a distressing film clip portraying an automobile accident and medical footage. Participants then recorded the frequency of intrusive thoughts about the film over the following week using a thought diary. Results revealed that trait anxiety, depression, and dissociation each predicted the development of intrusive thoughts about the film.

The aim of the present study was to extend prior research on the relationship between trait emotional characteristics and intrusive thoughts by including a measure of disgust propensity. Given that this study represents the first examination of the role of disgust propensity in predicting intrusive thoughts, we utilized a distressing film paradigm as an analogue traumatic stressor in a sample of healthy undergraduates (e.g., Holmes and Bourne 2008; Laposa and Alden 2008). The goal of the study was to examine disgust propensity specifically as a predictor of intrusive thoughts after viewing the film. In order to evaluate the influence of this trait independent of emotional characteristics known to be predictive of intrusive thoughts, we controlled for level of anxiety and depression. We hypothesized that individuals with elevated levels of disgust propensity would experience a greater number of intrusive thoughts immediately after watching a film depicting graphic trauma-relevant footage. Moreover, given that disgust and anxiety appear to operate on partially independent mechanisms, we hypothesized that the effect of disgust on intrusive thoughts would occur independent of pre-existing trait characteristics (i.e., trait anxiety and depression) and emotionality after the film (i.e., state anxiety).

\section{Method}

\section{Participants}

Participants comprised 38 students recruited from the undergraduate participant pool to complete a study on emotional reactivity to stress. Racial makeup of the sample was: $69 \%$ Caucasian, $13 \%$ Asian, $8 \%$ Hispanic/Latino, 5\% Black, and, $5 \%$ other or mixed race. To prevent inducing undue stress, participants who had experienced a traumatic event and were currently experiencing PTSD symptoms at or above the mean severity of samples used in analogue PTSD studies (e.g., Moser et al. 2007) were excluded from participation (see "Procedures" section). Eight individuals were excluded on this basis, resulting in a final sample of 30 individuals. Of the participants who endorsed experiencing a trauma, 7 reported accidents, 6 non-sexual assault, 5 natural disasters, 3 life threatening illness, and 1 combat.

Materials

Film

Participants were shown a brief film clip depicting graphic footage of individuals with severe burns. The clip showed the individuals' bodies and faces covered in burns, as well as their burned skin being removed in a hospital setting. This film was taken from prior research evaluating emotional reactivity to films (Gross and Levenson 1995).

\section{Measures}

\section{Posttraumatic Stress Symptoms}

PTSD symptoms were assessed using the Posttraumatic Diagnostic Scale (PDS; Foa et al. 1997). The PDS is a 49-item questionnaire with items designed to map onto the DSM-IV diagnostic criteria for PTSD. The questionnaire begins with an assessment of the nature and number of trauma(s) experienced by the individual. Next, symptom severity is assessed over the past month in each of the symptom categories: avoidance, re-experiencing, arousal. All items are scored on a zero to three scale, with higher values indicating greater symptom severity. The PDS has satisfactory agreement with the Structured Clinical Interview for DSM-IV (First et al. 1995; kappa $=.65$, agreement $=82 \%$, sensitivity $=.89, \quad$ specificity $=.75 ; \quad$ Foa et al. 1997) and the Clinician Administered PTSD Scale (agreement $=72 \%$; Adkins et al. 2008).

\section{State and Trait Anxiety}

The State Trait Anxiety Inventory (STAI; Spielberger et al. 1983) was used the measure trait and state anxiety at baseline, and also to measure state anxiety after the film. The STAI is a 40-item questionnaire; 20 items reflect current state anxiety and 20 items reflect more general feelings of trait anxiety. This measure possesses adequate psychometric characteristics (test-retest reliability $=.54$; Spielberger et al. 1970). 


\section{Depression}

Depression was assessed using the Beck Depression Inventory-II (BDI-II; Beck et al. 1996). The BDI-II questionnaire contains 21-items assessing depressive symptoms over the previous 2 weeks. This measure has strong psychometric properties.

\section{Disgust}

Disgust was assessed using the Disgust-Scale Revised (DS-R; Haidt et al. 1994, modified by Olatunji et al. 2007e). This questionnaire includes 25 items wherein participants are asked to rate level of disgust or discomfort with potentially disgust-eliciting scenarios (e.g., "You see maggots on a piece of meat in an outdoor garbage pail."). The DS-R is moderately correlated with disgust propensity $(r=.37)$, and to a lesser extent disgust sensitivity $(r=.29)$ as assessed with the Disgust Propensity and Sensitivity ScaleRevised (van Overveld et al. 2006). For the purposes of the present study, items were modified as per recommendations by Olatunji et al. (2007e) such that all response options ranged from 0 (strongly disagree/not disgusting at all) to 4 (strongly agree/extremely disgusting).

\section{Manipulation Checks and Participant Feedback}

Participants were also administered 10-point single-item ratings assessing (a) how much attention they paid to the film (ranging from no attention at all to complete attention; Holmes et al. 2004), and (b) how unpleasant the film was (extremely unpleasant to extremely pleasant). Participants were also administered a feedback questionnaire inquiring as to their hypothesis about the study's purpose to evaluate whether demand influenced the relationship between participants' self-rated disgust and intrusions.

\section{Thought Monitoring Task}

Frequency of intrusive thoughts about the film was measured using a 5 min thought monitoring task (adapted from Nixon et al. 2007). Participants were instructed to close their eyes and focus on relaxing for a $5 \mathrm{~min}$ period after the film. Participants were told to indicate each time they experienced an intrusive thought about the film by clicking a hand-held event marker.

\section{Procedure}

Participants were tested individually, and completed the study for course credit. Participants began the experiment by completing the consent form and initial self reports (PDS, STAI, BDI, DS-R). Participants scoring above 5 on

the PDS were excused after completion of the self reports; individuals who did not endorse a history of trauma or who were 5 or below on the PDS completed the remaining portions. Next, remaining participants watched the film on a computer monitor situated approximately $30 \mathrm{~cm}$ from their eyes. After the film, participants were given a STAI-S questionnaire, as well as a questionnaire containing the manipulation check items. Next, participants completed the thought monitoring task (see "Measures" section). The experimenter left the room during the film and thought monitoring task. After the film, participants completed the feedback questionnaire. Participants were fully debriefed after the study and given contact information and referrals in the event that they experienced significant distress as a result of the procedures. No participants expressed significant distress during the probe in the debriefing, and no participants contacted the experimenters at a later date.

\section{Results}

Reaction to Film, Manipulation Checks and Participant Feedback

Table 1 presents data on characteristics of the sample, state anxiety after the film, ratings for pleasantness of the film, and number of intrusions. Consistent with prior studies using distressing films (e.g., Holmes et al. 2004), results indicated that in general participants paid attention to the film $(M=8.7, \mathrm{SD}=1.5)$. Moreover, neither disgust propensity nor anxiety were correlated with self report of attention paid to the film $(P$ 's $>.5)$. A paired samples $t$ test conducted on STAI-S indicated that participants experienced a significant increase in anxiety as a result of the film, $t(29)=2.9$, $P<.01$. Most (83\%) of participants reported having at least one intrusive thought about the film during the thought monitoring period, similar to other studies (e.g., $72 \%$ in Laposa and Alden 2008). Based on the open-ended responses

Table 1 Sample characteristics and film reactivity items

\begin{tabular}{lc}
\hline $\begin{array}{l}\text { Women, number } \\
(\%)\end{array}$ & $19(63 \%)$ \\
Age (SD) & $19.4(1.0)$ \\
Education in years & $13.3(4.3)$ \\
STAI-T & $33.3(9.0)$ \\
STAI-S & $31.6(7.1)$ \\
BDI & $6.0(8.0)$ \\
PSST & $1.5(1.5)$ \\
DS-R & $52.8(14.9)$ \\
Post-film STAI-S & $34.9(8.2)$ \\
Pleasantness & $2.2(1.5)$ \\
Number of & $4.7(2.0)$ \\
$\quad$ intrusions & \\
\hline
\end{tabular}


Table 2 Bivariate correlations between anxiety, depression, disgust sensitivity, post-film state anxiety, and number of intrusions

\begin{tabular}{lllllll}
\hline Measure & 1 & 2 & 3 & 4 & 5 & 6 \\
\hline 1. STAI-T & 1.00 & & & & & \\
2. STAI-S & $.82^{* *}$ & 1.0 & & & & \\
3. BDI & $.82^{* *}$ & $.62^{* *}$ & 1.00 & & & \\
4. DS-R & .21 & .24 & .18 & 1.00 & & \\
5. Post-film STAI-S & $.69^{* *}$ & $.67^{* *}$ & $.69^{* *}$ & .24 & 1.00 & \\
6. Intrusions & .15 & .29 & .25 & $.53^{* *}$ & .24 & 1.00
\end{tabular}

STAI-T: Spielberger State-Trait Anxiety Inventory-Trait Version, STAI-S: Spielberger State-Trait Anxiety Inventory-State Version, $\mathrm{BDI}-\mathrm{II}=$ Beck Depression Inventory II, DS-R $=$ Disgust ScaleRevised

$* P<.05 ; * * P<.01$

on the participant feedback questionnaire, no participants accurately ascertained the study's purpose or hypotheses (i.e., that self-reported feelings of disgust were related to how the individual reacted to the film).

\section{Relationship Between Disgust, Anxiety, Depression and Intrusive Thoughts}

We computed Pearson's correlations to examine the relationship between trait characteristics (anxiety, depression, and disgust propensity) and emotional reactivity to the film (i.e., STAI-S after the film), as well as intrusions. Results indicated that disgust propensity was the only trait characteristic that was significantly associated with number of intrusions about the film, $r(30)=.53, P=.002$ (see Table 2).

Next, hierarchical regression analyses were used to test the hypothesis that level of disgust propensity would predict number of intrusions after viewing the film, independent of, trait anxiety and depression. Trait anxiety (STAI$\mathrm{T}$ ), and depression (BDI) were entered in step one of the regression. Disgust propensity (DS-R) was entered in step two of the regression analysis. Table 3 presents the results of the hierarchical regression analysis. No significant predictors emerged in step one. Results from step two of the analysis revealed that disgust propensity independently predicted number of intrusions, controlling for trait-characteristics, $\Delta R^{2}=.26, P<.01, f^{2}=.35 .^{1}$ In addition, semi-partial correlations indicated that disgust propensity was associated with intrusions, controlling for anxiety and depression $(r=.51)$. We also re-conducted these analyses with state anxiety after the film as a predictor, to determine whether disgust remained a significant predictor of

\footnotetext{
${ }^{1}$ Because women tend to report greater disgust than men (e.g., Haidt et al. 1994), we analyzed data including gender. The pattern of results did not differ, and disgust sensitivity remained an independent predictor of number of intrusions, $\Delta R^{2}=.18, P<.02$.
}

Table 3 Hierarchical regression analysis with trait characteristics

\begin{tabular}{|c|c|c|c|c|}
\hline \multirow[t]{2}{*}{ Predictor } & \multicolumn{4}{|c|}{ Intrusions } \\
\hline & $B$ & SE $B$ & $\beta$ & $\Delta R^{2}$ \\
\hline Step 1 & & & & .07 \\
\hline STAI-T & -.03 & .07 & -.14 & \\
\hline BDI & .09 & .08 & .363 & \\
\hline Step 2 & & & & $.26 * *$ \\
\hline STAI-T & -.06 & .06 & -.25 & \\
\hline BDI & .09 & .07 & .36 & \\
\hline DS-R & .07 & .02 & $.52 * *$ & \\
\hline
\end{tabular}

STAI-T: Spielberger State-Trait Anxiety Inventory-Trait Version, BDI-II $=$ Beck Depression Inventory II, DS-R = Disgust ScaleRevised

$* P<.05 ; * * P<.01$

Table 4 Hierarchical regression analysis with trait characteristics and anxiety reactivity

\begin{tabular}{lcccc}
\hline Predictor & \multicolumn{2}{l}{ Intrusions } & & \\
\cline { 2 - 5 } & $B$ & SE $B$ & $\beta$ & .07 \\
\hline Step 1 & & & & \\
STAI-T & -.03 & .07 & -.14 & \\
BDI & .09 & .08 & .36 & \\
Step 2 & & & & .02 \\
STAI-T & -.05 & .08 & -.22 & \\
BDI & .08 & .09 & .29 & \\
Post-film STAI-S & .05 & .07 & .20 & \\
Step 3 & & & & $.25 * *$ \\
STAI-T & -.06. & .07 & -.28 & \\
BDI & -.08 & .08 & .32 & \\
Post-film STAI-S & .03 & .06 & .10 & \\
DS-R & .07 & .02 & $.51^{* *}$ & \\
\hline
\end{tabular}

STAI-T: Spielberger State-Trait Anxiety Inventory-Trait Version, BDI-II = Beck Depression Inventory II, STAI-S: Spielberger StateTrait Anxiety Inventory-State Version, DS-R = Disgust ScaleRevised

$* P<.05 ; * * P<.01$

intrusive thoughts. Table 4 presents these results. Disgust propensity remained a significant predictor of number of intrusions, controlling for trait-characteristics as well as post-film anxiety level, $\Delta R^{2}=.25, P<.01, f^{2}=.33$.

\section{Discussion}

Results from the present study revealed that high levels of disgust propensity were associated with a greater number of thoughts about a distressing film immediately after viewing it. Moreover, disgust propensity predicted number of film-related thoughts when controlling for pre-existing 
trait anxiety and depression. This effect remained significant after controlling for post-film state anxiety, suggesting that the effect of disgust propensity is not simply a correlate of general negative affect. This distinction lends support to separate emotional dimensions of fear versus disgust (Olatunji et al. 2007c). The present findings are consistent with prior research suggesting that pre-existing emotional characteristics may predict the subsequent development of intrusive thoughts after analogue traumatic stressors (e.g., Laposa and Alden 2008).

Extant literature suggests that experiencing or witnessing certain traumatic events may elicit an array of aversive emotions, including disgust (e.g., McNally 2002). Although prior studies have demonstrated that certain forms of negative emotional reactions to trauma are associated with development of PTSD symptoms (e.g., shame and anger; Andrews et al. 2000), disgust reactions to trauma have remained relatively unexplored. To our knowledge, this is the first study to examine disgust propensity as a predictor of intrusive thoughts after an analogue traumatic stressor. Our results suggest that disgust propensity may be one factor that predicts recurring intrusive cognitions after an event involving witnessing injury or bodily harm. Specifically, individuals who are prone to experiencing relatively elevated levels of disgust may experience a greater number of intrusive thoughts about this type of event after it occurs.

Disgust is primarily an emotion of repulsion, and avoidance of repugnant and potentially harmful stimuli. One potential explanation for the link between disgust and intrusive thoughts may be cognitive avoidance. Disgust propensity has been shown to predict greater behavioral avoidance of disgust-eliciting cues in individuals with symptoms of OCD (Deacon and Olatunji 2007). If individuals with relatively high disgust propensity perceive trauma-relevant stimuli to be more aversive they may engage in mental strategies to try to avoid trauma-relevant thoughts. A large body of literature suggests that deliberately attempting to avoid or suppress unwanted thoughts has paradoxical consequences, frequently leading to an increase in the unwanted thought (e.g., Wenzlaff and Wegner 2000). In the present study, it is possible that individuals with higher disgust propensity attempted to suppress thoughts about the film, and subsequently experienced a greater number of intrusive cognitions about it. Future research might evaluate this cognitive avoidance hypothesis by examining the relationship between disgust propensity and cognitive regulation strategies in traumaexposed individuals.

Alternatively, disgust may play a role in attentional processes associated with viewing and remembering the film. Research suggests that disgust stimuli are associated with biased attentional processing, particularly for individuals with high disgust propensity (Charash and McKay
2002; Cisler et al. 2009). For example, individuals with symptoms of OCD (i.e., high contamination fears) demonstrate difficulty disengaging attention from disgust-relevant cues (Cisler and Olatunji 2010). Although participants' level of disgust propensity was not associated with self-reported attention to the film, it is possible that automatic (i.e., unintentional, non-conscious; Cisler et al. 2009) attentional processing of the film stimuli differed based on level of disgust propensity. Participants high in disgust propensity may have experienced difficulty directing attention away from particularly disgusting aspects of the film, such as the victim's injuries, relative to less disgust-prone individuals. Assuming that these graphic aspects of the film are more salient or arousing, one might expect to observe a greater frequency of intrusions noted for these individuals during the thought monitoring task. Alternatively, attentional biases may have influenced thoughts about the film during the thought monitoring task. If individuals who are disgust prone have difficulty disengaging attention from disgust cues, distracting oneself from disgusting memories or reminders of the film may be more difficult for these individuals during thought monitoring. In either case, biases in attentional processing may have influenced cognitive processing related to the film. Research is needed to delineate contributions of disgust and anxiety to such attentional processes.

In conjunction with prior studies suggesting elevated disgust in PTSD, the present findings may have implications for treatment approaches. Most empirically based treatment programs for individuals with PTSD focus primarily learning-based models of fear and anxiety. While these emotions undoubtedly play a role in trauma response, growing research suggests that other emotional reactions may also be important for trauma recovery (e.g., shame; Andrews et al. 2000). Although the present research was conducted in an analogue student sample, results suggest that disgust is one emotional reaction that may be related to recurrent memories in individuals who have been exposed to certain types of trauma. Research suggests that learning and extinction processes for fear and disgust reactions may be related, but operate differentially to some extent. For example, evidence from other clinical disorders such as OCD suggests disgust reactivity is relatively resistant to extinction (Mason and Richardson 2010; Olatunji et al. 2007a, 2009b) and appraisals of phobic stimuli as disgusting may persist in spite of fear extinction (de Jong et al. 2000). These differential extinction processes may be one explanation for variability in response or gain maintenance for individuals undergoing traditional exposure therapy (Olatunji et al. 2007b, 2009b). Although disgust habituation has not been examined empirically in PTSD, the presence of disgust during and after traumatic events (e.g., Feldner et al. 2010) and the relationship between disgust 
propensity and intrusive thoughts about an analogue trauma in the present study suggest that targeting disgust may be one consideration for future treatment outcome research.

The present study has a number of limitations. First, because this study recruited a small analogue sample of students, the results may not generalize to clinical samples (e.g., individuals with a diagnosis of PTSD). Future studies might assess high-risk individuals prior to trauma exposure to more fully elucidate the role of disgust propensity in predicting PTSD development (e.g., assessing military personnel pre-deployment, then evaluating diagnostic status after combat exposure). Second, for the purposes of the present study intrusions were only monitored in the laboratory immediately after viewing the film. This aspect of the study was designed to allow for optimal experimental control, and to capture intrusive thoughts when they are likely to be most frequent (i.e., immediately post-stressor). However, it does not allow for the evaluation of the effect's longevity. Future work in this area might provide participants with an intrusion diary to keep for a pre-determined amount of time post-stressor, in order to determine the effect of disgust propensity on intrusions after leaving the laboratory. Similarly, this research would also benefit from assessing the nature of the film-related thoughts (e.g., distress, perception of controllability). A third limitation of the present study is the lack of direct assessment of disgust elicited by the film. As the present study used a film that specifically depicted bodily injury, which may directly elicit disgust (e.g., Olatunji et al. 2005), further study is needed to determine the distinct contribution of disgust and anxiety reactivity as a result of the film. Future work utilizing a control condition (e.g., neutral or fear-specific film) would also allow for further delineation of the distinct role of disgust relative to other emotions. Moreover, because the injury component of the film may have directly elicited disgust, research is also needed to determine whether the relationship between disgust propensity and intrusive thoughts generalizes to other types of trauma-relevant stimuli (e.g., a film depicting rape). Finally, the present study evaluated disgust propensity, as indexed by the DS-R. Although the DS-R is the most widely used scale used to assess disgust reactions (Olatunji et al. 2008b; Tybur et al. 2009), this measure primarily assesses the tendency of the individual to feel disgusted by different types of stimuli. Thus, future work would benefit from measuring different aspects of disgust, including disgust sensitivity (i.e., intolerance of feeling disgusted), in the context of examining reactions to potentially traumatic events.

In summary, the present study indicates that higher levels of disgust propensity are associated with a greater number of film-related thoughts following an analogue traumatic stressor. Disgust propensity predicted additional variance in the number of thoughts participants had about the film during a subsequent thought monitoring period, independent of anxiety and depression. Results suggest that disgust may warrant further exploration in the context of PTSD. That is, disgust may be an emotional reaction to experiencing or witnessing trauma, while disgust propensity may be a potential predictor of cognitive reactivity to trauma.

Acknowledgments We would like to thank Salena McCaslin for her help with data collection. The preparation of this manuscript was supported by grants from the National Institutes of Health awarded to the first (1F31MH088170-01) and second author (01R34 MH07300401, R34 MH077129-01).

Open Access This article is distributed under the terms of the Creative Commons Attribution Noncommercial License which permits any noncommercial use, distribution, and reproduction in any medium, provided the original author(s) and source are credited.

\section{References}

Adkins, J. W., Weathers, F. W., McDevitt-Murphy, M., \& Daniels, J. B. (2008). Psychometric properties of seven self-report measures of posttraumatic stress disorder in college students with mixed civilian trauma exposure. Journal of Anxiety Disorders, 22, 1393-1402.

American Psychiatric Association. (2000). Diagnostic and statistical manual of mental disorders (4th ed., text revision). Washington, DC: Author.

Andrews, B., Brewin, C. R., Rose, S., \& Kirk, M. (2000). Predicting PTSD symptoms in victims of violent crime: The role of shame, anger, and childhood abuse. Journal of Abnormal Psychology, 109(1), 69-73. doi:10.1037/0021843X.109.1.69.

Beck, A. T., Steer, A., \& Brown, K. (1996). Beck depression inventory-II. San Antonio, TX: Harcourt Brace.

Brewin, C. R., Andrews, B., \& Rose, S. (2000a). Fear, helplessness, and horror in posttraumatic stress disorder: Investigating DSMIV criterion A2 in victims of violent crime. Journal of Traumatic Stress, 13(3), 499-509. doi:10.1023/A:1007741526169.

Brewin, C. R., Andrews, B., \& Valentine, J. D. (2000b). Metaanalysis of risk factors for posttraumatic stress disorder in trauma-exposed adults. Journal of Consulting and Clinical Psychology, 68(5), 748-766. doi:10.1037/0022-006X.68.5.748.

Brewin, C. R., Dalgleish, T., \& Joseph, S. (1996). A dual representation theory of posttraumatic stress disorder. Psychological Review, 103(4), 670-686. doi:10.1037/0033-295X.103.4.670.

Charash, M., \& McKay, D. (2002). Attention bias for disgust. Journal of Anxiety Disorders, 16(5), 529-541. doi:10.1016/S08876185(02)00171-8

Cisler, J. M., \& Olatunji, B. O. (2010). Components of attentional biases in contamination fear: Evidence for difficulty in disengagement. Behaviour Research and Therapy, 48(1), 74-78. doi: 10.1016/j.brat.2009.09.003.

Cisler, J. M., Olatunji, B. O., Lohr, J. M., \& Williams, N. L. (2009). Attentional bias differences between fear and disgust: Implications for the role of disgust in disgust-related anxiety disorders. Cognition and Emotion, 23(4), 675-687. doi:10.1080/026999 30802051599.

Dalgleish, T., \& Power, M. J. (2004). Emotion-specific and emotionnon-specific components of posttraumatic stress disorder (PTSD): Implications for a taxonomy of related 
psychopathology. Behaviour Research and Therapy. Special Issue Festschrift Special Issue for John Teasdale, 42(9), 1069-1088. doi:10.1016/j.brat.2004.05.001.

de Jong, P. J., \& Muris, P. (2002). Spider phobia: Interaction of disgust and perceived likelihood of involuntary physical contact. Journal of Anxiety Disorders, 16(1), 51-65. doi:10.1016/ S0887-6185(01)00089-5.

de Jong, P. J., Vorage, I., \& van den Hout, Marcel. A. (2000). Counterconditioning in the treatment of spider phobia: Effects of disgust, fear, and valence. Behaviour Research and Therapy, 38(11), 1055-1069. doi:10.1016/S0005-7967(99)00135-7.

Deacon, B., \& Olatunji, B. O. (2007). Specificity of disgust sensitivity in the prediction of behavioral avoidance in contamination fear. Behaviour Research and Therapy, 45(9), 2110-2120. doi: 10.1016/j.brat.2007.03.008.

Ehlers, A., \& Clark, D. M. (2000). A cognitive model of posttraumatic stress disorder. Behaviour Research and Therapy, 38(4), 319-345. doi:10.1016/S0005-7967(99)00123-0.

Fairbrother, N., Newth, S. J., \& Rachman, S. (2005). Mental pollution: Feelings of dirtiness without physical contact. Behaviour Research and Therapy, 43(1), 121-130. doi:10.1016/j.brat. 2003.12.005.

Fairbrother, N., \& Rachman, S. (2004). Feelings of mental pollution subsequent to sexual assault. Behaviour Research and Therapy, 42(2), 173-189. doi:10.1016/S0005-7967(03)00108-6.

Feldner, M. T., Frala, J., Badour, C., Leen-Feldner, E. W., \& Olatunji, B. O. (2010). An empirical test of the association between disgust and sexual assault. International Journal of Cognitive Therapy. Special Issue Disgust and Psychopathology, 3(1), 11-22. doi:10.1521/ijct.2010.3.1.11.

Fergus, T. A., \& Valentiner, D. P. (2009). The disgust propensity and sensitivity scale-revised: An examination of a reduced-item version. Journal of Anxiety Disorders, 23(5), 703-710. doi: 10.1016/j.janxdis.2009.02.009.

First, M. B., Spitzer, R. L., Williams, J. B. W., \& Gibbon, M. (1995). Structured clinical interview for DSM-IV-patient edition (SCID-P). Washington, DC: American Psychiatric Press.

Foa, E. B., Cashman, L., Jaycox, L., \& Perry, K. (1997). The validation of a self-report measure of posttraumatic stress disorder: The posttraumatic diagnostic scale. Psychological Assessment, 9(4), 445-451. doi:10.1037/1040-3590.9.4.445.

Foa, E. B., \& Kozak, M. J. (1986). Emotional processing of fear: Exposure to corrective information. Psychological Bulletin, 99(1), 20-35. doi:10.1037/0033-2909.99.1.20.

Foy, D. W., Sipprelle, R. C., Rueger, D. B., \& Carroll, E. M. (1984). Etiology of posttraumatic stress disorder in vietnam veterans: Analysis of premilitary, military, and combat exposure influences. Journal of Consulting and Clinical Psychology, 52(1), 79-87. doi:10.1037/0022-006X.52.1.79.

Gross, J. J., \& Levenson, R. W. (1995). Emotion elicitation using films. Cognition and Emotion, 9(1), 87-108. doi:10.1080/026999 39508408966.

Haidt, J., McCauley, C., \& Rozin, P. (1994). Individual differences in sensitivity to disgust: A scale sampling seven domains of disgust elicitors. Personality and Individual Differences, 16(5), 701-713. doi:10.1016/0191-8869(94)90212-7.

Haidt, J., Rozin, P., McCauley, C., \& Imada, S. (1997). Body, psyche, and culture: The relationship between disgust and morality. Psychology and Developing Societies. Special Issue Cultural Constructions and Social Cognition Emerging Themes, 9(1), 107-131. doi:10.1177/097133369700900105.

Hathaway, L. M., Boals, A., \& Banks, J. B. (2010). PTSD symptoms and dominant emotional response to a traumatic event: An examination of 0RW1S34RfeSDcfkexd09rT2DSMIV1RW1S34RfeSDcfkexd09rT2 criterion A2. Anxiety, Stress and Coping An International Journal, 23(1), 119-126. doi: 10.1080/10615800902818771.

Herba, J. K., \& Rachman, S. (2007). Vulnerability to mental contamination. Behaviour Research and Therapy, 45(11), 2804-2812. doi:10.1016/j.brat.2007.07.010.

Holmes, E. A., \& Bourne, C. (2008). Inducing and modulating intrusive emotional memories: A review of the trauma film paradigm. Acta Psychologica, 127(3), 553-566. doi:10.1016/ j.actpsy.2007.11.002.

Holmes, E. A., Brewin, C. R., \& Hennessy, R. G. (2004). Trauma films, information processing, and intrusive memory development. Journal of Experimental Psychology General, 133(1), 3-22. doi:10.1037/0096-3445.133.1.3.

Kessler, R. C., Sonnega, A., Bromet, E., \& Hughes, M. (1995). Posttraumatic stress disorder in the national comorbidity survey. Archives of General Psychiatry, 52(12), 1048-1060. Retrieved from www.csa.com.

Laposa, J. M., \& Alden, L. E. (2008). The effect of pre-existing vulnerability factors on a laboratory analogue trauma experience. Journal of Behavior Therapy and Experimental Psychiatry, 39(4), 424-435. doi:10.1016/j.jbtep.2007.11.002.

Mason, E. C., \& Richardson, R. (2010). Looking beyond fear: The extinction of other emotions implicated in anxiety disorders. Journal of Anxiety Disorders, 24(1), 63-70. doi:10.1016/ j.janxdis.2009.08.007.

McNally, R. J. (2002). Disgust has arrived. Journal of Anxiety Disorders, 16(5), 561-566. doi:10.1016/S0887-6185(02)00174-3.

Moser, J. S., Hajcak, G., Simons, R. F., \& Foa, E. B. (2007). Posttraumatic stress disorder symptoms in trauma-exposed college students: The role of trauma-related cognitions, gender, and negative affect. Journal of Anxiety Disorders, 21(8), 1039-1049. doi:10.1016/j.janxdis.2006.10.009.

Nixon, R. D. V., Nehmy, T., \& Seymour, M. (2007). The effect of cognitive load and hyperarousal on negative intrusive memories. Behaviour Research and Therapy, 45(11), 2652-2663. doi: 10.1016/j.brat.2007.06.010.

Olatunji, B. O., Babson, K. A., Smith, R. C., Feldner, M. T., \& Connolly, K. M. (2009a). Gender as a moderator of the relation between PTSD and disgust: A laboratory test employing individualized script-driven imagery. Journal of Anxiety Disorders, 23(8), 1091-1097. doi:10.1016/j.janxdis.2009.07.012.

Olatunji, B. O., Cisler, J. M., Deacon, B. J., Connolly, K., \& Lohr, J. M. (2007a). The disgust propensity and sensitivity scale-revised: Psychometric properties and specificity in relation to anxiety disorder symptoms. Journal of Anxiety Disorders, 21(7), 918-930. doi:10.1016/j.janxdis.2006.12.005.

Olatunji, B. O., Elwood, L. S., Williams, N. L., \& Lohr, J. M. (2008a). Mental pollution and PTSD symptoms in victims of sexual assault: A preliminary examination of the mediating role of trauma-related cognitions. Journal of Cognitive Psychotherapy, 22(1), 37-47. doi:10.1891/0889.8391.22.1.37.

Olatunji, B. O., Forsyth, J. P., \& Cherian, A. (2007b). Evaluative differential conditioning of disgust: A sticky form of relational learning that is resistant to extinction. Journal of Anxiety Disorders, 21(6), 820-834. doi:10.1016/j.janxdis.2006.11.004.

Olatunji, B. O., Haidt, J., McKay, D., \& David, B. (2008b). Core, animal reminder, and contamination disgust: Three kinds of disgust with distinct personality, behavioral, physiological, and clinical correlates. Journal of Research in Personality, 42(5), 1243-1259. doi:10.1016/j.jrp.2008.03.009.

Olatunji, B. O., Lohr, J. M., Sawchuk, C. N., \& Patten, K. (2007c). Fear and disgust responding to heterogeneous blood-injectioninjury stimuli: Distinctions from anxiety symptoms. Journal of Psychopathology and Behavioral Assessment, 29(1), 1-8. doi: 10.1007/s10862-006-9025-x. 
Olatunji, B. O., Lohr, J. M., Sawchuk, C. N., \& Westendorf, D. H. (2005). Using facial expressions as CSs and fearsome and disgusting pictures as UCSs: Affective responding and evaluative learning of fear and disgust in blood-injection-injury phobia. Journal of Anxiety Disorders, 19(5), 539-555. doi:10.1016/ j.janxdis.2004.05.002.

Olatunji, B. O., \& Sawchuk, C. N. (2005). Disgust: Characteristic features, social manifestations, and clinical implications. Journal of Social and Clinical Psychology, 24(7), 932-962. doi:10.1521/ jscp.2005.24.7.932.

Olatunji, B. O., Sawchuk, C. N., Lohr, J. M., \& de Jong, P. J. (2004). Disgust domains in the prediction of contamination fear. Behaviour Research and Therapy, 42(1), 93-104. doi:10.1016/ S0005-7967(03)00102-5.

Olatunji, B. O., Williams, N. L., Lohr, J. M., Connolly, K. M., Cisler, J., \& Meunier, S. A. (2007d). Structural differentiation of disgust from trait anxiety in the prediction of specific anxiety disorder symptoms. Behaviour Research and Therapy, 45(12), 3002-3017. doi:10.1016/j.brat.2007.08.011.

Olatunji, B. O., Williams, N. L., Tolin, D. F., Abramowitz, J. S., Sawchuk, C. N., Lohr, J. M., et al. (2007e). The disgust scale: Item analysis, factor structure, and suggestions for refinement. Psychological Assessment, 19(3), 281-297. doi:10.1037/10403590.19.3.281.

Olatunji, B. O., Wolitzky-Taylor, K. B., Willems, J., Lohr, J. M., \& Armstrong, T. (2009b). Differential habituation of fear and disgust during repeated exposure to threat-relevant stimuli in contamination-based OCD: An analogue study. Journal of Anxiety Disorders, 23(1), 118-123. doi:10.1016/j.janxdis. 2008.04.006.

Ozer, E. J., Best, S. R., Lipsey, T. L., \& Weiss, D. S. (2003). Predictors of posttraumatic stress disorder and symptoms in adults: A meta-analysis. Psychological Bulletin, 129(1), 52-73. doi:10.1037/0033-2909.129.1.52.

Petrak, J., Doyle, A., Williams, L., Buchan, L., \& Forster, G. (1997). The psychological impact of sexual assault: A study of female attenders of a sexual health psychology service. Sexual and Marital Therapy, 12(4), 339-345. Retrieved from www.csa.com.

Radomsky, A. S., \& Elliott, C. M. (2009). Analyses of mental contamination: Part II, individual differences. Behaviour Research and Therapy, 47(12), 1004-1011. doi:10.1016/j.brat. 2009.08.004.

Regambal, M. J., \& Alden, L. E. (2009). Pathways to intrusive memories in a trauma analogue paradigm: A structural equation model. Depression and Anxiety, 26(2), 155-166. doi:10.1002/da. 20483.
Rozin, P., Lowery, L., \& Ebert, R. (1994). Varieties of disgust faces and the structure of disgust. Journal of Personality and Social Psychology, 66(5), 870-881. doi:10.1037/0022-3514.66.5.870.

Sawchuk, C. N., Lohr, J. M., Westendorf, D. H., Meunier, S. A., \& Tolin, D. F. (2002). Emotional responding to fearful and disgusting stimuli in specific phobics. Behaviour Research and Therapy, 40(9), 1031-1046. doi:10.1016/S0005-7967(01)00093-6.

Shin, L. M., McNally, R. J., Kosslyn, S. M., Thompson, W. L., Rauch, S. L., Alpert, N. M., Metzger, L. J., Lasko, N. B., Orr, S. P., \& Pitman, R. K. (1999). Regional cerebral blood flow during scriptdriven imagery in childhood sexual abuse-related PTSD: A PET investigation. The American Journal of Psychiatry, 156(4), 575-584. Retrieved from www.csa.com.

Spielberger, C. D., Gorsuch, R. C., \& Lushene, R. E. (1970). Manual for the State trait anxiety inventory. Palo Alto, CA: Consulting Psychologists Press.

Spielberger, C. D., Gorsuch, R. L., Lushene, R., Vagg, P. R., \& Jacobs, G. A. (1983). Manual for the State-trait anxiety inventory. Palo Alto, CA: Consulting Psychologist Press.

Stein, M. B., Walker, J. R., Hazen, A. L., \& Forde, D. R. (1997). Full and partial posttraumatic stress disorder: Findings from a community survey. The American Journal of Psychiatry, 154(8), 1114-1119. Retrieved from www.csa.com.

Tolin, D. F., Woods, C. M., \& Abramowitz, J. S. (2006). Disgust sensitivity and obsessive-compulsive symptoms in a non-clinical sample. Journal of Behavior Therapy and Experimental Psychiatry. Special Issue Disgust Sensitivity in Anxiety Disorders, 37(1), 30-40. doi:10.1016/j.jbtep.2005.09.003.

Tybur, J. M., Lieberman, D., \& Griskevicius, V. (2009). Microbes, mating, and morality: Individual differences in three functional domains of disgust. Journal of Personality and Social Psychology, 97(1), 103-122. doi:10.1037/a0015474.

van Overveld, W. J. M., de Jong, P. J., Peters, M. L., Cavanagh, K., \& Davey, G. C. L. (2006). Disgust propensity and disgust sensitivity: Separate constructs that are differentially related to specific fears. Personality and Individual Differences, 41, $1241-1252$.

Wenzlaff, R. M., \& Wegner, D. M. (2000). Thought suppression. Annual Review of Psychology, 51, 59-91. doi:10.1146/annurev. psych.51.1.59.

Woody, S. R., McLean, C., \& Klassen, T. (2005). Disgust as a motivator of avoidance of spiders. Journal of Anxiety Disorders, 19(4), 461-475. doi:10.1016/j.janxdis.2004.04.002.

Woody, S. R., \& Teachman, B. A. (2000). Intersection of disgust and fear: Normative and pathological views. Clinical Psychology Science and Practice, 7(3), 291-311. doi:10.1093/clipsy/7.3.291. 